\title{
CRITÉRIOS PARA DIFERENCIAÇÃO E AUTONOMIA DO DIREITO DIANTE DOS DEMAIS SISTEMAS NORMATIVOS E A COERCITIVIDADE
}

CRITERIA FOR THE DIFFERENTIATION AND AUTONOMY OF THE LAW UNDER THE OTHER REGULATORY SYSTEMS AND THE COERCITIVITY

\author{
João Maurício Adeodato ${ }^{1}$ \\ Faculdade de Direito de Vitória/ES
}

\section{Resumo}

O texto enfrenta a questão da distinção entre o direito e os demais tipos de normas éticas, como as religiosas e morais. Parte das raízes aristotélicas do problema e observa os diversos critérios construídos pela teoria geral do direito ao longo do tempo, tais como heteronomia, alteridade, bilateralidade e outros, arguindo a tese de que podem ser todos reduzidos à coercitividade, entendida como ameaça de violência organizada autorizada por sanção, e rebatendo as objeções anticoercitivistas.

Palavras-Chaves

Critérios distintivos do direito. Norma jurídica. Coercitividade. Objeções à coercitividade.

\section{Abstract}

The text addresses the issue of the distinction between law and other types of ethical norms, such as religion and morals. It departs from the Aristotelian roots of the problem and observes the various historical criteria built by the general theory of law, such as heteronomy, alterity, bilaterality and others, arguing the thesis that they can all be reduced to coercitivity, understood as the threat of organized violence authorized by sanction. It also seeks to respond to the objections against coercitivity as a distinctive character of law.

\footnotetext{
${ }^{1}$ Professor do Programa de Pós-graduação da Faculdade de Direito de Vitória. Pesquisador 1-A do CNPq. Currículo completo em: http://lattes.cnpq.br/8269423647045727
} 


\section{Keywords}

Distinguishing features of law. Legal norms. Coercitivity. Objections to coercitivity.

\section{Distinção entre caráter e atributo como base teórica}

Ao analisar o processo de separação do direito das outras ordens normativas (da religião, da moral, da política etc.), necessidade trazida pelo surgimento do Estado moderno e sua pretensão de monopólio do direito, e as explicações dos filósofos para legitimar essa diferenciação, foi importante, na tarefa de dizer o direito, na jurisdição, a teoria de Aristóteles que distingue caráter e atributo.

O caráter é um elemento presente na definição de algo, sem o qual aquele algo deixa de ser o que é. É assim da "essência" ("quididade", do latim quiditas) daquele algo. O atributo é um elemento contingente, compõe o objeto, mas não faz parte de sua identidade individual. Na linguagem comum, a palavra "característica" é ambiguamente utilizada para expressar ambas as ideias, de caráter e de atributo. Daí dizer-se que tanto o número de cromossomos (essência) quanto os cabelos negros (acidente) são "características" de fulano ou beltrano.

Mesmo assim, a distinção atravessa a cultura ocidental e estende-se para outras expressões como necessidade e contingência, permanência e mudança, essencial e existencial, ser-assim e ser-aí, fundamental e eventual etc.

Esses critérios teóricos para separar as esferas do direito e da religião respondiam a uma necessidade política, pois o Estado emergente precisava de apoio para combater a filosofia universalista da Igreja, instituição onipresente que penetrava em todos os aspectos da vida humana, pública e privada. Quando Christian Thomasius sugere o primeiro desses critérios, retomando Aristóteles em 1705, sua 
teoria vai servir também para enfraquecer a onipresença da Igreja Católica Romana e apoiar os Estados nacionais em formação.

Não se faz revolução sem ideias e a emancipação do Estado da Igreja não poderia ser diferente. Claro que, para isso se firmar, era necessário que a Igreja perdesse seu poder, o Estado não conseguiria simplesmente tomá-lo.

A era moderna trouxe um grande desenvolvimento dos instrumentos de violência e das formas de controle e coação, pelo qual poucos conseguem dominar muitos, mas isso pouco muda, pois não muda a situação; os governos sempre detiveram muito mais potencial de violência que seus cidadãos:

Revolucionários são aqueles que sabem quando o poder está largado na rua e quando eles podem tomá-lo. Um levante armado somente jamais levou a uma revolução².

Em outras palavras, para Arendt revoluções não são "feitas" e rebeldes só tomam o poder quando o governo já o perdeu.

Sempre corroborando a inseparabilidade entre teoria e prática, os pensadores concentram-se na tentativa de separar o direito das demais ordens normativas e constroem uma série de critérios diferenciadores. Cada um deles considera diferentes aspectos do fenômeno jurídico e, entendidos de forma complementar, apresentam utilidade até os dias atuais, nos quais a instituição dominante ainda é o Estado nacional moderno.

Enquanto a religião católica se divide diante dos movimentos protestantes, o direito do Estado emergente precisa ser separado da religião, aproveitando o enfraquecimento político de uma Igreja

${ }^{2}$ ARENDT, Hannah. Thoughts on politics and revolution, em Crises of the Republic. New York/London: Harvest/HBJ, 1972, p. 20: "The revolutionaries are those who know when power is lying in the street and when they can pick it up. Armed uprising by itself has never yet led to a revolution." 
corrompida, e também da moral, vez que a complexidade social e sua pulverização ética fazem conviver várias morais contraditórias, reduzindo seu papel na coesão social.

Como o Estado moderno pretende o monopólio da jurisdição e não pode haver vários direitos sob um mesmo Estado, uma dessas perspectivas morais vence a luta pelo direito e impõe-se a todos, mesmo àqueles que dela não partilham. A complexidade social faz com que essa vitória daquela perspectiva moral seja temporária e a todo tempo confrontada com aquelas derrotadas, que não são eliminadas e permanecem em protesto na luta pelo direito. O direito passa a ser o único ambiente ético comum porque é a única forma de ética que é coercitiva.

\section{Exterioridade, heteronomia, alteridade e bilateralidade}

Além da distinção entre caracteres e atributos, colocada por Aristóteles, a primeira nota distintiva entre direito e moral/religião também é acentuada por ele: a exterioridade.

Não se pode dizer que o pensamento de Aristóteles é o mesmo dos pré-iluministas, mais de mil e quinhentos anos depois. Ele nem está preocupado, a rigor, com o direito, mas sim com a justiça enquanto virtude, caracterizada pela proporção entre as pessoas, logo como virtude intersubjetiva. Mesmo assim, como justiça e direito não estão claramente distintos em sua Ética a Nicômaco, não está errado dizer que Aristóteles é o grande precursor das tentativas de distinguir as ordens éticas. Muitos outros autores se dedicaram ao tema, acentuando ora um ora outro aspecto e utilizando diferentes palavras: intersubjetividade, exterioridade, exigibilidade, bilateralidade e outras a seguir analisadas. Muito longe de serem sinônimas, essas expressões têm, contudo, uma mesma base filosófica. 
É só com o jusnaturalismo racionalista de Thomasius que surge a tentativa de fixar explicitamente um critério distintivo: a exterioridade da conduta humana. As condutas que não podem ser empiricamente observadas pelos demais seres humanos estariam sujeitas às regras da moral e da religião, no foro interno, acessível apenas à consciência de cada um e a Deus. Se alguém vai à missa porque tem interesse em fazer negócios com a Igreja, por exemplo, a norma religiosa não é cumprida, pois a convicção interior, a interioridade, é indispensável.

Isso põe em discussão um problema importante: afinal, as condutas internas são inatingíveis e daí irrelevantes para o direito, ou as intenções e pensamentos devem ser consideradas nos conflitos jurídicos?

Aristóteles, apesar de ter chamado atenção para o caráter "social" do direito, é partidário da ideia de que o direito cuida também da intenção do agente. ${ }^{3}$ A influência dessa ideia na civilização universal é muito grande. Inúmeros pensadores a defendem sob os mais variados argumentos ${ }^{4}$.

De uma perspectiva realista, Thomasius tinha toda razão: o trabalho dos profissionais do direito só pode atingir os atos exteriorizados e, no máximo, simplesmente inferir sua intenção. Quando se refere a atos internos, o direito o faz a partir de condutas exteriorizadas, não há como conhecer o foro interno.

${ }^{3}$ ARISTOTLE. Rhetoric. I, 13, 1374a. The works of Aristotle, trad. W. Rhys Roberts, Col. Great Books of the Western World. Chicago: Encyclopaedia Britannica, 1990, vol. 8, p. 598.

${ }^{4}$ Por todos REALE, Miguel. Filosofia do Direito. São Paulo: Saraiva, 2002 (20a ed.), p. 653-671. 
Um exemplo da atualidade do embate é oferecido nos textos dos artigos 110 e 112 do Código Civil de 2002, cuja exegese literal se afigura contraditória.

Art. 110. A manifestação de vontade subsiste ainda que o seu autor haja feito a reserva mental de não querer o que manifestou, salvo se dela o destinatário tinha conhecimento.

Art. 112. Nas declarações de vontade se atenderá mais à intenção nelas consubstanciada do que ao sentido literal da linguagem.

No primeiro texto da lei, mesmo com a obscura expressão "reserva mental de não querer o que manifestou", a exterioridade parece prevalecer na "manifestação de vontade". No segundo, a interioridade parece decisiva no privilégio da intenção. Mas "intenção" deve ser entendida metaforicamente: aquilo que os atos da pessoa fazem aparecer sua intenção. Um exemplo esclarecerá a visão empírica realista aqui defendida.

Imagine um caso, um sujeito A que troca tapas com um sujeito B e na hora diz que vai matá-lo, para logo depois deixar tudo aquilo de lado, esquecendo mesmo o ocorrido. Semanas depois A vai caçar de madrugada em um lugarejo no interior, inteiramente desavisado de que a família de $B$ é daquela mesma cidade há décadas - o que é público e notório, mas A desconhece - e de que $\mathrm{B}$ está temporariamente visitando a família. Aí A atira em um animal, erra e a bala ricocheteia duas vezes na rocha, atingindo mortalmente $B$, no momento em que dava a mamadeira noturna ao filho de dois anos, na varanda do sítio.

Como o parágrafo acima é um relato, segundo ele A não teve em seu íntimo a menor intenção de matar. "Na realidade" foi um acidente ou, quando muito, um crime culposo. Mas é muito provável que A seja sentenciado à pena máxima, com todas as circunstâncias agravantes presentes na lei: motivo torpe, crime premeditado, sem oportunidade de defesa para a vítima, na calada da noite. 
A visão idealista contrária à exterioridade parte de duas suposições nada evidentes: a de que os atos humanos necessariamente partem de intenções definidas e a de que é possível conhecê-las empiricamente.

O embate entre a visão realista de Pufendorf (o que importa é a manifestação dotada de exterioridade) e a visão idealista (há uma intenção "verdadeira" por trás das aparências) revela-se, por exemplo, na referência a atos praticados de boa e má fé, com consequências jurídicas muito diferentes, fazendo crer que a intenção do foro interno é muito importante para o direito.

Diante das críticas feitas ao critério de exterioridade/interioridade para caracterizar o direito, desde seu ressurgimento no século XVII, outros critérios foram tentados. No século XVIII, o filósofo Immanuel Kant vai colocar três outros, pensando em separar o direito tanto da religião quanto da moral.

Sugere então um segundo critério, a heteronomia do direito que o separa da autonomia da moral. Como os nomes demonstram, a moral é autônoma (auto-nomos, auto norma) no sentido de serem suas normas de competência e de eleição exclusivas do próprio sujeito; o direito é heterônomo por serem suas normas fixadas independentemente do sujeito que a elas está submetido. A adesão do sujeito à moral ou à religião precisa ser de livre vontade, autônoma; o indivíduo não precisa, contudo, aderir às regras do direito, basta que as obedeça: daí seu caráter heterônomo.

Um terceiro critério é a alteridade, que enfatiza a teleologia ou finalidade do sistema normativo, que, no caso do direito, precisa necessariamente levar em consideração a pessoa do outro (alter), ao contrário das normas dotadas de identidade (id), as quais buscam o aperfeiçoamento do próprio indivíduo, isoladamente considerado. $\mathrm{O}$ 
direito preocupa-se com as relações entre os sujeitos; a moral e a religião, com os próprios sujeitos.

Observe-se que esses dois últimos critérios, apontados por Kant, são claramente aprimoramentos conceituais do critério da exterioridade. Sim, pois a heteronomia, o caráter de a norma ser estabelecida por outrem, só é possível com normas que se referem a condutas empiricamente observáveis; da mesma maneira a alteridade, que só pode visar aperfeiçoar relações entre pessoas se essas relações forem exteriorizadas.

Para as normas de etiqueta e de política, por exemplo, assim como no direito, tampouco importam as convicções internas do sujeito, a interioridade, a identidade, a autonomia.

O critério da unilateralidade/bilateralidade também leva a malentendidos porque a tradição jurídica só menciona esses dois termos, porém quer significar três situações e três tipos de normas diferentes: na primeira, unilateral, a relação se dá entre o indivíduo e ele mesmo. No segundo tipo de relação há pelo menos dois sujeitos, mas apenas um é vinculado pela norma, o outro é somente parte do contexto. No terceiro tipo há também pelo menos dois lados, só que ambos são vinculados pela norma, isto é, a cada dever de um corresponde um poder de outro, no sentido de exigir o cumprimento desse dever.

Exemplificando: no primeiro tipo a norma incide sobre um polo (sujeito, indivíduo, parte, lado) e um vínculo: "a pessoa deve ser coerente consigo mesma". No segundo há dois polos, contudo apenas um vínculo: “a pessoa deve amar o próximo", pois não é possível obrigar alguém a amar o próximo. Na terceira situação apresentam-se dois polos e dois vínculos, para cada dever alguém tem o direito (subjetivo) de fazer o direito (objetivo) obrigar o cumprimento da norma: "o comprador deve pagar o preço acertado". 
Diante do problema de haver duas palavras significantes para três situações significadas, a doutrina criou variações por meio de adjetivos como os sentidos "forte" e "fraco" ou "amplo" e "estrito": unilateralidade, bilateralidade em sentido fraco ou amplo, bilateralidade em sentido forte ou estrito. Nesse sentido estrito, a bilateralidade é apresentada como um critério distintivo do direito. Com dois polos e dois vínculos, ela é chamada de "atributiva"5.

A bilateralidade consiste em o direito situar sempre o indivíduo perante outro, estabelecendo a relação jurídica, numa união necessária de direitos e obrigações. Essa é, assim, uma bilateralidade não apenas de polos mas também de vínculos, pois não somente envolve dois sujeitos, como o fazem muitas normas morais e religiosas de bilateralidade simples, mas também dois vínculos jurídicos, uma vez que um polo tem o dever e outro, a faculdade de exigir sua satisfação. Nesse conceito amplo podem ser inseridas expressões mais específicas, como interferência intersubjetiva, exigibilidade ou impedibilidade. Embora possam fazer referências a outros sujeitos, as demais ordens normativas não configuram sua conduta de forma necessária, reduzindo-os a um papel meramente passivo.

\section{Coerção, coercibilidade, coercitividade, sanção e coação}

Os primeiros critérios visavam apenas fundamentar a diferenciação do direito diante da religião e da moral, e foram relativamente bem-sucedidos. Eles não bastam, contudo, para diferençar o direito dos usos sociais, como as regras de etiqueta e protocolo, que também se caracterizam por exterioridade, heteronomia e alteridade.

\footnotetext{
${ }^{5}$ REALE, Miguel. Filosofia do Direito. São Paulo: Saraiva, 2002 (20 ed.), p. 691 s.
} 
Além disso a emancipação do direito não teve apenas esse desiderato político de combater o poder da Igreja Católica, adquiriu depois uma ambição cientificista e o objetivo passou a ser isolar o objeto de estudo do jurista, assim como lhe fornecer uma metodologia específica. E pela primeira vez vai surgir uma instituição que se arvora o monopólio da jurisdição, ou seja, para o Estado, direito é aquilo que o próprio Estado define como direito. Mas a necessidade prática de separar o direito das ordens normativas também dotadas de exterioridade, heteronomia e alteridade persistia, assim como de uma teoria que lhe desse suporte.

Aparece então uma ideia conexa, mas a partir de outra perspectiva, a relação entre direito e força, e até violência, facilmente perceptível para o senso comum, mas objeto de controvérsias e fonte de diferentes conceitos na história das ideias.

O conceito mais suave é o que Durkheim denominou hábito geral de obediência, também chamado de coerção. Os seres humanos, como a maioria dos primatas, tendem à imitação. Daí a inclinação para seguir a maioria das regras se configurar como a estratégia mais cômoda para viver. Os ordenamentos normativos, mesmo depois de diferenciados, convergem nesse ponto de induzir um comportamento social mais uniforme, vez que sempre há ônus em divergir do ambiente, das pessoas em torno. Assim o direito, a moral, a religião, a política, a etiqueta etc. todos apontam na mesma direção de um comportamento comum. Durkheim chamou atenção para essa pressão generalizada e indiferenciada, esse "hábito geral de obediência".

Ocorre que essa tendência não é forte o suficiente para conter as condutas desviantes. Para estas o direito apresenta uma ameaça mais específica, acena com consequências desagradáveis para o agente que optar pela conduta contrária a seus comandos, quando não bastam a religião ou a moral. Essa ameaça, que existe em todo tipo de norma, no 
direito pode chegar às raias da violência, ou seja, o sujeito que optou pelo ilícito em tese não pode resistir a essa violência, seja sobre sua pessoa, seja sobre seu patrimônio. Essa ameaça se denomina a coercitividade do direito, diz-se também da norma jurídica.

Kant dá ao $\S 4^{\circ}$ de sua introdução à teoria jurídica, dentro da Metafísica dos Costumes, o título Das Recht ist mit der Befugnis zu zwingen verbunden (o direito está ligado à autorização para coagir) ${ }^{6}$. A coercitividade é a possibilidade que o direito tem de se fazer valer, pela possibilidade de coagir o sujeito a cumpri-lo, é a principal característica do poder, a ameaça de violência irresistível e legítima.

Hobbes ressalta que, diante das características humanas, nem as leis da natureza nem os pactos são suficientes sem a coercitividade:

Pois as leis da natureza... por si mesmas, sem o medo de algum poder que provoque sua observância, são contrárias às nossas paixões naturais, as quais nos levam a parcialidade, orgulho, vingança e semelhantes. E acordos, sem a espada, não passam de palavras e não têm qualquer força para garantir a segurança de alguém ${ }^{7}$.

Antes dele, Maquiavel já chamara atenção para isso, de forma ainda mais explícita:

...não é razoável que quem está armado obedeça com gosto a quem

${ }^{6}$ KANT, Immanuel. Die Metaphysik der Sitten. Werkausgabe, in zwölf Bände (em 12 v.), WEISCHEDEL, Wilhelm (Hrsg.). Frankfurt a. M.: Suhrkamp, 1977, v. VIII, p. 338 e 339. Pelas referências originais, p. A-B 35-36.

7 Hobbes, Thomas. Leviathan, or, matter, form and power of a commonwealth ecclesiastical and civil. London / Chicago / Toronto: Robert Hutchins / Encyclopaedia Britannica, 1952, cap. XVII, p. 99: "For the laws of nature, as justice, sanity, modesty, mercy, and, in sum, doing to others as we would be done to, of themselves, without the terror of some power to cause them to be observed, are contrary to our natural passions, that carry us to partiality, pride, revenge, and the like. And Convenants, without the sword, are but words and got no strength to secure a man at all." 
não está, e que o príncipe desarmado viva seguro entre servidores em armas.

Assim, é necessário a um príncipe, para se manter, que aprenda a poder ser mau e que se valha ou deixe de valer-se disso segundo a necessidade ${ }^{8}$.

Mais recentemente, em um debate brasileiro e com origens linguísticas, surge o problema de distinguir coercitividade e coercibilidade, o que vai depender de como se define cada termo. Para um lado, o direito é coercível, suscetível de execução pela força física, isto é, dotado de coercibilidade, a virtualidade ou possibilidade da coação. Já a coercitividade designa a efetividade da coação que tinha sido apenas ameaçada pela coercibilidade, significa que houve a aplicação da força física ${ }^{9}$. Este é um argumento baseado na distinção aristotélica entre potência e ato ou entre possibilidade e efetividade.

Do outro lado tem-se uma objeção etimológica: as pessoas é que são dotadas de coercibilidade, são coercíveis, coercibilidade é a susceptibilidade de sofrer a coação, por isso não faz sentido dizer que o direito é dotado de coercibilidade. Ele, o conjunto de normas jurídicas, é dotado de coercitividade, a possibilidade de exercer, de aplicar a coação. Ambas são virtuais, potenciais, possibilidades, mas uma é passiva e a outra, ativa. $\mathrm{O}$ mesmo que ocorre com as palavras compreensível e compreensivo, por exemplo. O compreensível é

8 Machiavelli, Niccolò. Il principe, em Opere (a cura de Mario Bonfantini), Milano/Napoli: Riccardo Ricciardi, s.d., cap. XIV, p. 47-48: "Perché da uno armato a uno disarmato non è proporzione alcuna; e non é ragionevole che chi é armato obidisca volentieri a chi è disarmato, e che il disarmato stia securo intra servitore armati." Idem , ibidem , cap XV, p. 50: “Onde é necesario a uno principe, volendo si mantenerse, imparare a potere essere buono, e usarlo e non l'usare secondo la necessità ."

${ }^{9}$ REALE, Miguel. Filosofia do Direito. São Paulo: Saraiva, 2002 (20a ed.), p. 657-658. 
passível de compreensão, é aquilo, aquele ou aquela que pode ser compreendido; o compreensivo é quem compreende ativamente.

Numa visão realista, o que interessa é o significado, não tem muita importância se o nome é este ou aquele, desde que se defina previamente cada um deles. O caráter distintivo do direito é a ameaça, fica claro que não a coação efetiva, pois não é viável que cada ato de cada cidadão seja vigiado e tornado efetivo. Sempre há a escolha entre o lícito e o ilícito, diante da ameaça de violência futura. Feita essa ressalva, diante da precisão terminológica sugerida acima, vai-se aqui escolher a expressão coercitividade.

Em suma, para aqueles que não se deixam levar pelo hábito de obediência de Durkheim nem intimidar pela ameaça da coercitividade, e mesmo assim optam pelo ilícito, o direito autoriza e legitima a prática da violência. Essa autorização é chamada de sanção da norma jurídica, a consequência atribuída pela prática da conduta ilícita. Sanção é a parte da norma jurídica que autoriza aquela ameaça do possível a se tornar efetiva, aplicada.

Caso essa autorização para prática da violência efetivamente se realize na esfera empírica, essa violência chama-se coação. A coação é sempre uma forma de violência, como aquela praticada por bandidos, mas a coação jurídica é legitimada exatamente pela prévia autorização da sanção da norma. São elos de uma corrente: pressão social difusa > coercitividade $>$ sanção $>$ coação. Para muitas pessoas basta a pressão social, para outras, necessária a coação.

Se nem toda norma é dotada de coercitividade e daí não ameaça com a violência, isso não significa que só a norma jurídica tenha sanção. Toda norma possui sanção em sua estrutura lógica e ela incide em caso de descumprimento. O que a norma jurídica tem de específico não é a sanção, mas sim a característica de que só a sanção do direito enseja a violência. A transgressão de uma norma religiosa provoca o 
abandono do pecador por Deus ou até sanções institucionalizadas como a excomunhão, terríveis para uma pessoa religiosa. O remorso é uma sanção moral que pode ser extremamente dolorosa para o individuo que tem moral. O escárnio e a exclusão do meio pelo descumprimento de normas de etiqueta podem ser sanções graves para certos ambientes sociais.

Mas dessas ordens normativas é possível se retirar, basta evitar o ambiente em que elas vigoram: não dar valor, não se importar com religião, moral, protocolos de usos sociais, lealdades políticas. Mas da incidência do direito ninguém escapa. Isso não significa que as normas jurídicas sejam sempre socialmente eficazes, ou seja, que sejam cumpridas ou tenha suas sanções efetivamente aplicadas; é frequente, sobretudo em países subdesenvolvidos da modernidade periférica, que criminosos escapem às instituições jurídicas ou até que sejam sancionados, mas não coagidos. A efetividade do direito é fenômeno fático e não apenas normativo, depende de fatores reais como uma polícia, um ministério público, um judiciário competentes.

Apesar de hoje não mais se constituir num debate decisivo na área jurídica, a inclusão da coercitividade como caráter distintivo do direito em face das demais ordens normativas, dando forma mais clara às necessidades de diferenciação funcional da sociedade complexa, foi útil ao Estado moderno e à filosofia juspositivista emergentes e teve papel importante na construção da ciência do direito. Se "direito" pode ser chamado de "ciência", só depende das definições de ambos os termos.

\section{Objeções à coercitividade como critério distintivo do direito}

Muitos participantes desse debate discordam de que a coercitividade possa ser colocada como um caráter distintivo do direito. Esses autores enfrentam a dificuldade de separar o direito das 
demais ordens normativas. Os de inspiração kantiana argumentam que o direito é uma parte da moral, mas isso não afasta o problema, pois um critério é necessário para separar espécie de gênero. $O$ próprio Kant enfrentou esse problema e simplesmente seguiu os pré-iluministas: o direito é dotado de exterioridade. Por isso, o imperativo categórico da moral e de toda a esfera ética é assim definido:

O imperativo categórico é, portanto só um único, que é este: age apenas segundo uma máxima tal que possas ao mesmo tempo querer que ela se torne uma lei universal. ${ }^{10}$

E a "lei geral do direito" expressa-se:

Assim a lei geral do direito é: age exteriormente de modo que o livre uso de teu arbítrio possa conciliar-se com a liberdade de todos segundo uma lei universal... ${ }^{11}$

As objeções anticoercitivistas podem ser classificadas segundo quatro ordens de argumentos: gnoseológica, axiológica, supra-estatal e infra-estatal.

Segundo os argumentos de ordem gnoseológica, não é suficiente definir um fenômeno empírico como o direito por critérios meramente formais, que procuram analisar estruturalmente os elementos componentes do objeto. Critérios analíticos podem servir para objetos ideais como os da geometria, mas não para o mundo real.

${ }^{10}$ KANT, Immanuel. Grundlegung zur Metaphysik der Sitten (1795). Werkausgabe — in zwölf Bände. W. WEISCHEDEL (Hrsg.). Frankfurt a.M.: Suhrkamp, 1977, vol. VII, p. A e B 52: "Der kategorische Imperativ ist also nur ein einziger, und zwar dieser: handle nur nach derjenigen Maxime, durch die du zugleich wollen kannst, da $\beta$ sie ein allgemeines Gesetz werde".

${ }^{11}$ KANT, Immanuel. Die Metaphysik der Sitten (1797). Werkausgabe - in zwölf Bände. W. WEISCHEDEL (Hrsg.). Frankfurt a.M.: Suhrkamp, 1977, vol. VIII, p. A e B 35: "Also ist das allgemeine Rechtsgesetz: handle äußerlich so, da $\beta$ der freie Gebrauch deiner Willkür mit der Freiheit von jedermann nach einem allgemeinen Gesetze zusammen bestehen könne..." (Grifei). 
Jamais se poderia dizer que se conhece a água a partir de sua definição como $\mathrm{H}_{2} \mathrm{O}$, por exemplo. Muito menos um conceito carregado de valores e escolhas éticas.

Outro argumento oriundo da teoria do conhecimento afirma que a coercitividade é um dado externo ao direito e tudo o que é externo é contingente, logo não pode fazer parte de suas características lógicas essenciais. Isso porque nem toda norma jurídica tem a sanção em sua estrutura lógica, o que confirmaria a tese anticoercitivista. Uma versão é afirmar que só a norma jurídica tem sanção coercitiva, aquela que autoriza a violência, pois aceita-se que toda norma tem sanção. Outra mais radical é colocar que não só a sanção é dispensável ao conceito de norma em geral, mas até ao de norma jurídica. Um exemplo seria a norma jurídica "Brasília é a Capital Federal" (art. 18, § $1^{\circ}$ da CF).

Os argumentos axiológicos apontam que a definição do direito a partir da coercitividade e demais critérios diferenciadores não apresentam conteúdo ético e assim qualquer postura pode ser protegida pelo direito; em outras palavras, o conteúdo ético torna-se irrelevante. Se a proteção aos direitos de igualdade é coercitivamente protegida naquela comunidade, isso é o direito. Mas se a tortura é admitida, também protegida coercitivamente, o apoio à tortura é $o$ valor que o direito garante. O critério distintivo da coercitividade assim abandonaria a ideia de justiça da qual o direito não se deve nem pode afastar.

A objeção supra estatal ao critério da coercitividade diz respeito ao próprio caráter jurídico do direito internacional. Afirma que muitas normas de direito internacional não têm caráter coercitivo e mesmo assim são jurídicas, só que com base na máxima pacta sunt servanda, pactos são obedecidos, suficiente para garantir o direito internacional como ramo do direito há pelo menos quatro séculos. 
Os argumentos de ordem infraestatal partem do chamado pluralismo jurídico, a ideia de que o Estado não monopoliza o direito e que diversas ordens jurídicas podem coexistir e concorrer em um mesmo ambiente. Assim, diante da ineficiência do Estado, que não consegue distribuir a todos sua justiça, surge um "direito achado na rua", "direito alternativo" ao estatal, "inoficial", o qual não é apoiado por sanções e nem dotado de coercitividade, mas é reconhecido pela comunidade como direito positivo e tem toda eficácia social.

Opta-se aqui pela tese de que todo direito é coercitivo. Quando determinada perspectiva moral se torna jurídica, coercitiva, passa a ser imposta a todos, independentemente de com ela estarem de acordo. Ela pode continuar sendo moral para alguns, para aqueles que têm a força para ver suas visões de mundo prevalecerem, mas será jurídica para todos.

Para responder às objeções de ordem lógica, o essencial é perceber que texto e norma, significante e significado, não se confundem, nunca coincidem. Por isso pode haver várias normas em um só artigo ou serem necessários dois ou mais artigos para compor uma norma. $\mathrm{O}$ art. 14 de Constituição brasileira, que disciplina a nacionalidade, contém várias normas diferentes. O art. 1521 do Código Civil estipula que "não podem casar... os ascendentes com os descendentes, os afins em linha reta" etc., sem mencionar qualquer sanção. Esta vai aparecer em outro artigo, 1548, que disciplina serem nulos os casamentos contraídos em desobediência a qualquer dos incisos do art. 1521. Ocorre então de a sanção estar em outro texto: em outro artigo ou mesmo em outra lei ou outro ramo do ordenamento jurídico. No outro exemplo mencionado logo acima, em caso de transgressão da prestação (conduta lícita) "Brasília é a Capital Federal", a sanção está adiante, no art. 34: haverá intervenção para I - "manter 
a integridade nacional" ou para III - "por termo a grave comprometimento da ordem pública”.

A chamada "sanção premial" tem outro significado e não deve ser confundida com a sanção coercitiva da norma jurídica aqui tratada. Trata-se de uma consequência favorável ao agente que cumpre devidamente a norma jurídica, tal como o abatimento de certa percentagem no pagamento de uma obrigação. Outra ambiguidade da palavra sanção é que designa também, no direito constitucional, uma das fases do processo legislativo ordinário.

As objeções de ordem axiológica se originam da recusa em reduzir o direito ao direito positivo. Haveria assim uma ética jurídica acima do poder de governo, isto é, nem tudo o que é justo se torna direito positivo e nem todo direito positivo é justo. Um problema para os anticoercitivistas é que, como não há um critério evidente para distinguir o direito empiricamente observável e o critério de justiça que o observador está utilizando, fica difícil definir a pauta de investigação e acabam por fazer filosofia moral e não do direito.

Essa metonímia de confundir espécie e gênero ou espécies de um mesmo gênero coopera para a confusão entre moral e justiça, entre justiça e direito. Sua origem está no enfraquecimento da religião na esfera pública e o consequente crescimento da moral na filosofia ocidental, estabelecido a partir dos ensinamentos do iluminismo, tendo por vezes levado a uma identificação entre ética e moral ou à ideia de que ética é o estudo da moral.

A resposta contrária à argumentação de que o direito internacional é um exemplo de que nem todo direito é coercitivo é feita casuisticamente e por meio de uma tautologia, dizendo o seguinte: o direito internacional é direito quando é coercitivo. Essas relações internacionais só podem ser consideradas direito se alguma 
força garantir sua coercitividade, quando as decisões não se conseguem impor trata-se de mera diplomacia ou política.

As exigências para proteção do meio ambiente, por exemplo, supostamente fixadas por normas de direito internacional, que são simplesmente ignoradas pelos maiores poluidores como os Estados Unidos e a China, não podem ser chamadas de normas jurídicas, pois são inteiramente inócuas. Normas de relações internacionais se tornam jurídicas quando as potências militares as apoiam e efetivam, como no caso da Resolução 678 do Conselho de Segurança da Organização das Nações Unidas quando da invasão do Iraque durante a Guerra do Golfo de agosto de 1990, bem de acordo com a definição de coercitividade dada acima.

Outra linha de argumentação anticoercitivista refere-se a normas produzidas à margem do direito oficial do Estado, o qual pretende monopolizar a jurisdição dentro das fronteiras de determinado território. Afirma que essas regras inoficiais podem ser jurídicas, sem ser coercitivas. Exemplos seriam aquelas exaradas por associações de moradores, líderes comunitários, prelados de igrejas e até órgãos estatais como comissários de polícia, delegados, juízes ${ }^{12}$.

Esse argumento foi analisado por Kelsen sob a metáfora "bando de salteadores", isto é, se seriam jurídicas as regras impostas a esse tipo de coletividade. Conclui que não são jurídicas por serem localizadas, sobretudo por não serem chanceladas pelo Estado. Isso faz o argumento depender do Estado, perfeitamente compreensível num

12 OLIVEIRA, Luciano. Sua excelência o comissário. Recife: PIMES/UFPE, 1984; e OLIVEIRA, Luciano e PEREIRA, Affonso César. Conflitos coletivos e acesso à justiça. Recife: OAB/ Massananga, 1988. ASCENSÃO, José de Oliveira (org.). Água Branca - pesquisa de um direito vivo. Recife: Ed. Universitária da UFPE, 1978, e SANTOS, Boaventura de Souza. O discurso e o poder - ensaio sobre a sociologia da retórica jurídica. Coimbra: Universidade de Coimbra, 1980. 
positivista estatalista como Kelsen ${ }^{13}$. A linha divisória de Kelsen não é ética, como no caso de Radbruch e jusnaturalismos em geral: o nazismo era contra a boa ética, mas era direito porque se apossou do Estado.

A resposta a essa objeção é: confunde coercitividade com coercitividade estatal. Isso porque as relações que os sociólogos chamam de direito infraestatal são coercitivas. O problema aparece quando esses costumes jurídicos funcionam contra legem, este é o crivo para saber se a resposta é positivista (jurídica é a regra coercitiva, venha de onde vier) ou positivista estatalista, kelseniana (jurídica é a regra que o Estado diz que é de direito). Para os estatalistas, a coercitividade dos costumes contra a lei do Estado não é coercitividade, porém pura violência.

Para os positivistas não estatalistas, também chamados de sociologistas, não há qualquer diferença - no que se refere ao critério para separar o direito das demais ordens normativas - entre a ameaça de violência que o Estado pretende monopolizar nos tempos modernos e as demais formas que as sociedades humanas desenvolveram para isso. O direito não surge com o Estado e os significados dos dois termos não se confundem.

Em resumo, ambas são positivistas e coercitivistas, mas Kelsen e seus discípulos estatalistas consideram que só as normas coercitivas postas pelo Estado podem ser chamadas de direito positivo. As normas não produzidas pelo Estado, as quais ele aceita e aplica, os costumes secundum legem e paeter legem, essas são jurídicas. Porém é no costume contra legem que está o critério: para os sociologistas é direito, para os estatalistas, não.

${ }^{13}$ KELSEN, Hans. Reine Rechtslehre. Wien: Verlag Österreich, 2000 (2. Vollständig neu bearbeitete und erweiterte Aufl. 1960), p. 45. Trad. portuguesa João Baptista Machado: Teoria pura do direito. Coimbra: Arménio Amado Ed., 1976, p. 74. 
O problema das teorias anticoercitivistas é que fica confusa a relação entre direito e moral, religião, etiqueta etc. Logicamente o estudo do direito estará tanto mais acurado quanto mais bem isolado esteja seu objeto. E a coercitividade do direito, única ordem ética que ameaça com a violência organizada, parece ser o que de melhor a teoria geral do direito construiu como critério distintivo. 